\title{
The effects of cue distinctiveness on odor-based context-dependent memory
}

\author{
RACHEL S. HERZ \\ Monell Chemical Senses Center, Philadelphia, Pennsylvania
}

\begin{abstract}
The distinctiveness of an ambient odor was examined in relation to its success as a cue in contextdependent memory. Distinctiveness was examined in terms of both cue novelty and contextual appropriateness. Two experiments were conducted in which three different ambient odors that varied in familiarity and contextual appropriateness were manipulated at an incidental word learning encoding session and at a free recall retrieval session $48 \mathrm{~h}$ later. Experiment 1 revealed that when a novel ambient odor (osmanthus) was the available context cue, word recall was better than in any other condition. Further, among familiar odor cues, recall was better with a contextually inappropriate odor (peppermint) than with a contextually appropriate odor (clean fresh pine). Experiment 2 confirmed that superior word recall with osmanthus and peppermint depended on the odor cue's being available at both encoding and retrieval, and that the relation of an odor to the situational context is a key factor for predicting its effectiveness as a retrieval cue.
\end{abstract}

According to the encoding specificity principle (Tulving, 1983) memory for material is enhanced when contextual stimuli encoded along with the target information are present at retrieval. It thus follows that if recall is improved in the presence of an odor, that odor must have been part of the encoding environment. Consistent with this proposition, several laboratories have shown that an ambient odor present at encoding and retrieval facilitates memory (Cann \& Ross, 1989; Schab, 1990; D. G. Smith, Standing, \& de Man, 1992). Nevertheless, some researchers have reported failing to obtain these effects (Bjork \& Richardson-Klavehn, 1989).

Why are context effects with odor cues not entirely reliable? It is uninformative to blame inconsistent findings on the capricious nature of environmental context effects, because when experimental methodologies are held constant (i.e., the use of incidental learning procedures and recall tests) reliable results are obtained in this domain (see Eich, 1980; Schab, 1990; S. M. Smith, 1988). Cue distinctiveness has been shown to be positively correlated with memorability (see Schmidt, 1991, for a review). Thus, inconsistent findings obtained with odor context cues may be related to their perceived distinctiveness. In particular, an odor's distinctiveness may vary as a function of the global context in which it is experienced (Dalton, 1993). An odor can be distinctive by being novel,

The author extends appreciation and thanks to Eric Eich for conceptual guidance and to Robert Crowder, Barry Green, Robert Greene, Geoffrey Loftus, Russ Mason, Frank Schab, and two anonymous reviewers for helpful comments on earlier versions of this article. Many thanks also to IFF for generously donating the odorants and related supplies used in the experiments. This research was conducted under an NSERC postdoctoral fellowship held by the author at the University of British Columbia. Correspondence concerning this article should be addressed to: R. Herz, Monell Chemical Senses Center, 3500 Market St., Philadelphia, PA 19104 (e-mail: herz@pobox.upenn.edu). and/or by being inappropriate to its context (e.g., the smell of leather in a bakery). The underlying assumption is that more attention is paid to the odor in these cases; hence the more deeply it may be processed and then serve to facilitate memory (Jacoby \& Craik, 1979; Schmidt, 1991).

The purpose of the present research was to investigate the effects of cue distinctiveness in relation to the success of odors as retrieval cues in context-dependent memory (CDM). Cue distinctiveness was evaluated both in terms of odor novelty (familiarity) and contextual appropriateness. The general prediction was that the effectiveness of an ambient odor context cue would be positively related to its distinctiveness.

\section{EXPERIMENT 1}

The aim of Experiment 1 was to examine the effects of odor cue distinctiveness in CDM by evaluating the contribution of cue familiarity and contextual appropriateness. Contextual appropriateness was defined by the thematic relevance of an odor (i.e., would the odor be expected?) within the global context of the experimental setting. An unexpected odor was considered to be contextually inappropriate and hence distinctive.

Three different ambient odor conditions that varied in familiarity and contextual appropriateness were compared with one another and a no-odor control condition. The three odorants chosen for comparison were osmanthus, peppermint, and clean fresh pine (common pine cleaner scent). Osmanthus is an unusual, Asian, floralfruity scent (see Warren \& Warrenburg, 1993). It was chosen as the novel and inappropriate odor for this research on the basis of a pretest study, in which osmanthus was selected by 10 independent raters as the most unusual/ unfamiliar odor out of four "pleasant-unfamiliar" scents. 
Thus, osmanthus was distinctive both because it was unfamiliar and because an Asian floral smell would not be expected within a laboratory setting. Peppermint and clean fresh pine were compared as familiar but differentially contextually appropriate (i.e., distinctive) odors. Earlier work has shown that these two odors are both rated as highly familiar (Herz \& Cupchik, 1992), but they differ in terms of how appropriate they are within a psychology laboratory. Peppermint is a distinctive odor in a psychology laboratory, because one does not expect to smell a strong peppermint candy scent in a laboratory setting. By contrast, the clean fresh pine scent used is a common pine cleaner disinfectant odorant, and thus would be expected within a laboratory environment (nondistinctive).

To disambiguate the effects of the ambient odor context cue from other potential environmental stimuli, the physical settings of the encoding and retrieval session rooms were varied so that no physical cues other than the ambient odor manipulated were the same in the two rooms. Subject sex was also examined, because there is some evidence of a female advantage for odor detection (Doty, Snyder, Huggins, \& Lowry, 1981) and odor-associated learning (Kirk-Smith, Van Toller, \& Dodd, 1983). It was predicted that cue effectiveness would be directly related to cue distinctiveness: Thus, osmanthus, a novel and contextually inappropriate odor, should be the most effective retrieval cue. Furthermore, a familiar odor cue that was distinctive within its global context (peppermint) should be a better retrieval cue than a familiar odor cue that was not distinctive within its global context (clean fresh pine).

\section{Method}

Odors. The odors used were osmanthus $(20 \%)$, peppermint $(10 \%)$, and clean fresh pine $(10 \%)$ chemical solutions in diethyl phthalate (DEP), provided by International Flavors and Fragrances. These concentrations yield average and comparable levels of odor intensity (Herz \& Cupchik, 1992; Warren \& Warrenburg, 1993). The mean pleasantness ratings for osmanthus, peppermint, and clean fresh pine were $7.25(S D=1.18), 6.19(S D=1.80)$, and 5.65 $(S D=1.31)$, respectively (based on a 9 -point rating scale, where $1=$ extremely unpleasant, $9=$ extremely pleasant; $n=16$ for each odor group). Odors were delivered by passive diffusion into the atmosphere of the laboratory. To achieve the appropriate ambient odor environment, 12 DEP pellets saturated with liquid odorant were placed in three bowls (4 pellets in each bowl). One bowl was placed near the subject's chair; the two other bowls were located at equidistant points in the laboratory. A floor fan set on low helped circulate the air. The experimenter assessed the room prior to each subject's entry to ensure that the smell had not faded, and refreshed the odor pellets as necessary. Rooms were completely aerated when there was any change in ambient environment, either because of subject artifact (e.g., perfume), or because of a change in odor experimental conditions. In the no-odor condition, there was no manipulated room scent.

Design and Procedure. Experiment 1 was a 4 (osmanthus, peppermint, clean fresh pine, no odor) $\times 2$ (male, female) betweensubjects design. Sixteen subjects were randomly assigned to the four odor experimental groups, with an equal number of males and females in each. The subjects participated in two experimental sessions (encoding and retrieval) separated by $48 \mathrm{~h}$. Word list learning was incidental during encoding, and memory for the words was tested by free recall at retrieval
Encoding session. On the encoding session day, the subject met the experimenter at her office and was led to the encoding session room situated in a quiet area on the bottom floor of the psychology building. This room was $14.5 \times 11 \mathrm{ft}$, windowless, carpeted, and furnished with tables, chairs, bookshelves, stereo equipment, and posters on the walls. Room illumination was moderate and provided by overhead fluorescent lighting. Ambient room temperature was approximately $17^{\circ} \mathrm{C}$. In the odor-present conditions, the subjects were alerted to the presence of the ambient odor with the following comment, so that a correct attribution between the odor and the environment would be made (Fernandez \& Glenberg, 1985; Herz, in press; Schab, 1990).

You may have noticed that this room has a certain smell to it. This is just how some of the rooms in this building happen to smell. The reason I draw your attention to it is because this experiment has to do with context, and smell is one aspect of the context you are in.

To further ensure that subjects attended to the room context (i.e., noticed the ambient odor), all subjects were given a Room Environment Questionnaire (REQ) (Herz, in press). The REQ asked for scalar ratings of the room's lighting, temperature, odor, appearance, and general comfort. Ratings obtained on the REQ were not statistically analyzed. Upon completing the REQ, the subjects were told that they would be left alone for $10 \mathrm{~min}$ and that they should relax and remain seated. It was explained that this was in order to familiarize them with the environment, and for experimental control. 'The purpose of leaving the subjects in the room for $10 \mathrm{~min}$ was to promote the encoding of the potential context cues that it provided (such as ambient odor). When the experimenter returned, Eich's autobiographical event generation procedure (Eich, Macaulay, \& Ryan, 1994) was conducted as the incidental word learning (IWL) task. The subjects were presented with $20 \mathrm{com}$ mon, concrete, semantically unrelated, and affectively neutral English nouns (e.g., pencil, airplane, key), selected from the Brown and Ure (1969) word norms as to-be-remembered (TBR) items. The subjects were read each target word one at a time and asked to describe, in a few sentences, an event that had happened to them that the word reminded them of. The subjects were told that the event had to be (1) a specific incident (as opposed to an everyday occurrence), and (2) from at least 1 month ago in time. These restrictions were imposed to ensure that the words were not superficially processed. The experimenter wrote down each event recounted. No time limit was given to the subjects for their event recollections; thus, the interval between TBR words was subject paced. Most subjects completed the IWL task within 25 min. The subjects were then thanked and asked to return in 2 days for further testing. No mention of future memory tests was ever made.

Retrieval session. Forty-eight hours later, the subject met the experimenter at her office and was led to the retrieval session room situated on the main floor of the psychology building between two busy offices. This room was $12.5 \times 10 \mathrm{ft}$, brightly lit, uncarpeted, and furnished with a desk, filing cabinet, and several bookshelves; there were no wall decorations. A large window with partially closed venetian blinds covered one wall, and the ambient room temperature was approximately $21^{\circ} \mathrm{C}$. No mention of ambient odor was made at the retrieval session, regardless of the odor condition. When seated, the subject filled out a new REQ. The subjects were then given a surprise free recall test for the words presented during the encoding session. The subjects were asked to try to recall as many words as they could from the first session, in any order, within $10 \mathrm{~min}$. Event reminiscences were encouraged, but only recalled target words were recorded. When the recall period was over, the subjects in the odor experimental groups were asked whether the room smelled the same as the encoding session room, and whether the room smell was familiar to them or not. The sub jects were then fully debriefed.

Subjects. Sixty-four University of British Columbia undergraduates ( 32 male and 32 female) participated in Experiment 1 
Comparison of Three Odors and a No Odor Control

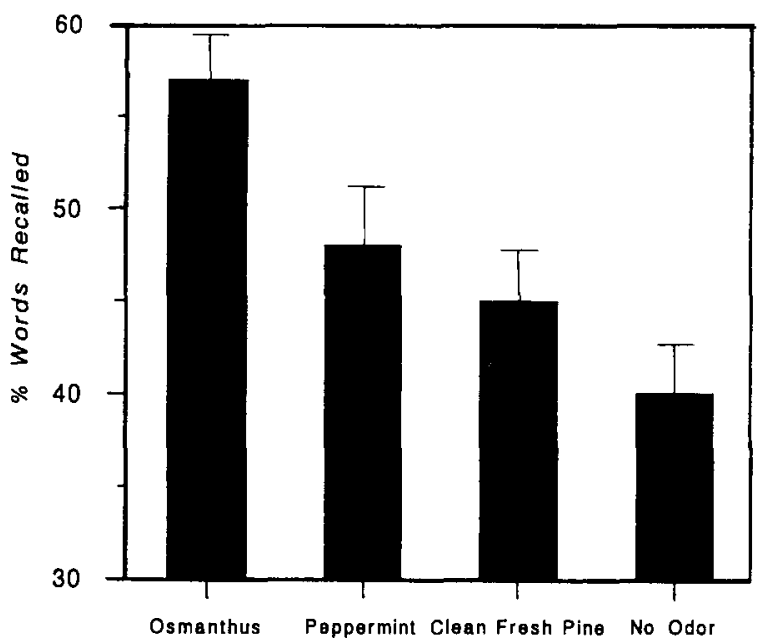

Figure 1. Mean ( $+S E M$ ) percent words recalled by subjects in each ambient odor group of Experiment 1.

in exchange for course credit. The subjects were individually tested and in good respiratory health. Nine of the 64 subjects replaced individuals who did not conform to the experimental criteria that (1) osmanthus be perceived as an unfamiliar odor, and (2) the encoding and retrieval session rooms be perceived as smelling the same. Of the 9 supplanted subjects, 4 replaced subjects in the osmanthus condition ( 2 male, 2 female) who said that the smell was familiar to them, and 5 replaced subjects in the peppermint (1 male, 1 female) and clean fresh pine ( 2 male, 1 female) conditions who claimed that the two rooms did not smell the same. All subjects in the osmanthus condition stated that the two rooms smelled the same, and all subjects in the peppermint and clean fresh pine condition reported that the room odor was familiar.

\section{Results and Discussion}

Figure 1 shows the percent of words correctly recalled as a function of ambient odor condition. As can be seen, there was a significant main effect for odor group $[F(3,56)$ $=7.20, p<.01]$.

Post hoc tests (Newman-Keuls, $p<.05$ ) confirmed that the subjects in the osmanthus condition recalled more words than did the subjects in any other group. Furthermore, the subjects in the peppermint condition recalled more words than did the subjects in the no-odor condition. However, the subjects in the clean fresh pine condition did no better than the subjects with no odor cue. There were no other significant differences between groups and no effects or interactions due to subject sex. These results are consistent with the predication that odor cue effectiveness would be proportional to cue distinctiveness. The most effective retrieval cue was osmanthus, followed by peppermint. Clean fresh pine, however, did not facilitate memory beyond a no-odor condition. Osmanthus was defined as distinctive by being both novel and contextually inappropriate, whereas peppermint was defined as distinctive by the single characteristic of being contextually inappropriate. By contrast, clean fresh pine was neither novel nor contextually inappropriate, and hence apparently ineffective.

\section{EXPERIMENT 2}

Experiment 1 demonstrated that osmanthus was a superior ambient odor context cue, followed by peppermint, but that clean fresh pine did not facilitate memory. These data were interpreted as supporting the prediction that odor cue effectiveness in CDM is directly proportional to the distinctiveness of the ambient odor. However, because the effects of ambient odor on memory were never examined in isolation, it cannot be entirely ruled out that the memory enhancements seen with osmanthus and peppermint were due to a facilitating effect of the odor at only one of the sessions. This explanation is particularly important to rule out because of the popularized belief that odors can have special effects by virtue of their intrinsic properties (e.g., aromatherapy).

The encoding specificity principle (Tulving, 1983) postulates that in order for memory to be facilitated by an environmental cue, the salient environmental elements (cues) of a learning context must also be present at retrieval. Accordingly, an odor should only be an effective context cue if it is present at both encoding and retrieval.

Experiment 2 was thus conducted to confirm that memory enhancements obtained in the presence of ambient odor were dependent on the odor context cue's being present at both encoding and retrieval. A second aim was to examine more fully the possible advantage of osmanthus as a novel retrieval cue in contrast to the other ambient odor conditions.

\section{Method}

Design and Procedure. Three separate substudies for the odors tested in Experiment 1 were conducted. Each substudy adhered to a 2 (odor present at encoding vs. odor absent at encoding) $\times 2$ (odor present at retrieval vs. odor absent at retrieval) $\times 2$ (male, female) between-subjects design. Eight subjects ( 4 males, $4 \mathrm{fe}-$ males) were randomly assigned to the four experimental groups in each substudy. The subjects participated in two sessions (encoding and retrieval) separated by $48 \mathrm{~h}$.

The experimental procedures for each substudy corresponded to Experiment 1, with the following exceptions. Half the subjects in each substudy experienced an ambient odor at only one session (either encoding or retrieval) and only 16 words (from the original 20) were presented as TBR items during encoding. Most subjects completed the IWL task within $20 \mathrm{~min}$. The testing procedures at retrieval were the same as in Experiment 1.

Subjects. One hundred and twenty-eight University of British Columbia undergraduates participated in Experiment 2 in exchange for course credit. Thirty-two ( 16 male, 16 female) subjects were randomly assigned to the osmanthus and peppermint substudies, and 64 ( 32 male, 32 female) subjects were randomly allocated to the clean fresh pine substudy. The subjects were individually tested and in good respiratory health. Eleven of the 128 subjects replaced individuals who did not conform to the experimental criteria that the encoding and retrieval session rooms be perceived as having the same smell. Of the 11 supplanted subjects, 2 replaced subjects in the osmanthus substudy, 2 replaced subjects in the peppermint substudy, and 7 replaced subjects in the clean fresh pine substudy. All the subjects in the osmanthus substudy 
stated that the room odor was unfamiliar, and all the subjects in the peppermint and clean fresh pine substudies reported that the room odor was familiar.

\section{Results and Discussion}

Figure 2 shows the percent of words correctly recalled by subjects in each condition of the three odor substudies. As can be seen, a significant interaction for odor presence at encoding and retrieval was confirmed for the osmanthus and peppermint substudies $[F(1,24)=18.97$, $p<.01$, and $F(1,24)=4.28, p<.05$, respectively]. Post hoc tests (Newman-Keuls, $p<.05$ ) verified that when the odor was present in both encoding and retrieval sessions, significantly more words were recalled than when the odor was present only at encoding, only at retrieval, or when no odor cue was available. There were no statistical differences between the mean number of words recalled in the latter three groups. From Figure 2 it is also apparent that the mean number of words recalled when the odor was present at encoding and retrieval in the osmanthus and peppermint substudies was virtually identical ( $M=62 \%$ for osmanthus, and $M=64 \%$ for peppermint). Thus, a novel odor was not a superior memory cue to a familiar distinctive odor in this experiment.

Thirty-two subjects were initially tested in the clean fresh pine substudy. The mean percentage of words recalled was $56 \%(S D=4.4 \%), 42 \%(S D=5.3 \%), 47 \%$ $(S D=5.8)$, and $50 \%(S D=3.6)$, for subjects in the odor present at both sessions, odor at study only, odor at test only, and no-odor groups, respectively. Analysis of variance did not yield any significant effects, but the pattern of performance was sufficiently similar to that of the osmanthus and peppermint groups to warrant further examination. Thus, 32 additional subjects were tested $(8$ more in each group) in the clean fresh pine substudy. Figure 2 shows the results for 64 subjects in the clean fresh pine

\section{Osmanthus}

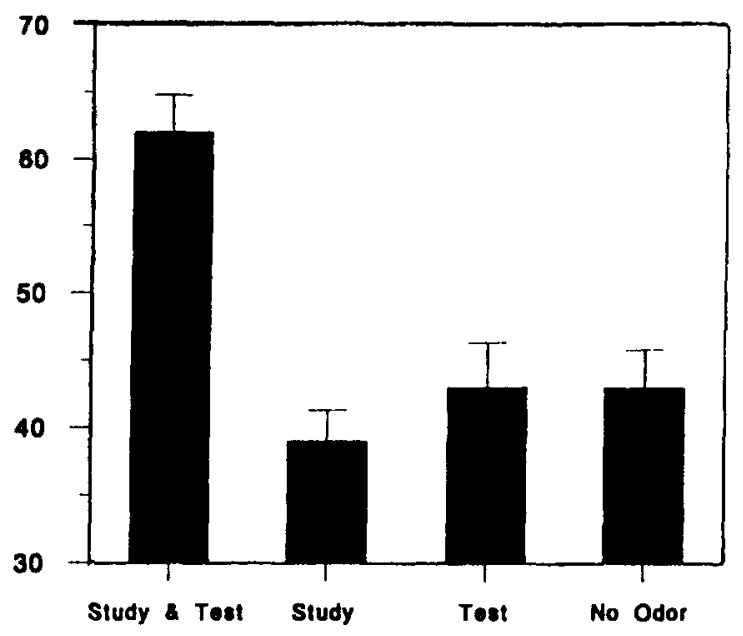

Peppermint



Clean Fresh Pine



Figure 2. Experiment 2 substudies: mean $(+S E M)$ percent words recalled as a function of odor presence or absence at encoding (study) and retrieval (test) sessions. 
substudy. Although the pattern of responding resembled that in the other odor substudies, no significant effects or interactions were obtained, and the trend toward higher recall for subjects in the odor at study and test condition was attenuated. No main effects or interactions were obtained as a function of subject sex in any substudy.

The results from Experiment 2 indicate that the memory enhancements produced with osmanthus and peppermint as ambient odor cues were dependent on the odor's being present at both encoding and retrieval, as predicted by encoding specificity (Tulving, 1983). Osmanthus and peppermint, salient elements of the learning environment, were encoded as part of the memory trace and thereby aided memory owing to their presence at retrieval. By contrast, clean fresh pine did not facilitate memory because it was not perceived as a distinctive (i.e., salient) environmental element and thus was not encoded as part of the memory trace. These results replicate those of Schab (1990) and corroborate prior work in which odors have been shown to be effective CDM cues (Cann \& Ross, 1989; Schab, 1990; D. G. Smith et al., 1992). Moreover, these data suggest that the relation of a cue to its global context is the most important determinant of cue effectiveness.

\section{GENERAL DISCUSSION}

The principle finding from the present experiments is that the contextual distinctiveness of an ambient odor will predict its effectiveness as a retrieval cue in CDM. A distinctive odor will be an effective retrieval cue, and a nondistinctive odor will not. These data are compatible with memory research in other modalities (Schmidt, 1991). The present data also show that odor cue distinctiveness is determined more by the contextual appropriateness of an odor than by its novelty.

The inconsistencies found with a novel ambient odor (osmanthus) suggest that perceived distinctiveness varies, and that novelty does not necessarily heighten the effectiveness of an odor context cue beyond sheer contextual distinctiveness. This is somewhat surprising, given that novel cues by definition have no prior associational referents and thus should be more easily associable to new material, and because proactive interference effects have been shown to be quite strong in odorassociated memory (Lawless \& Engen, 1977). More novel odors should be tested in this paradigm before the possible advantages of odor novelty in CDM are ruled out.

Cue salience has long been shown to be central to the success or failure of CDM experimentation (see Eich, 1980). Differences in contextual distinctiveness between the odors tested in the present experiments may therefore explain inconsistencies in past research of odor-based CDM. Schab (1990) examined the effects of chocolate, apple-cinnamon, and moth ball as ambient odor context cues. All three are familiar but contextually inappropriate (distinctive) odors within a psychology laboratory. In the present research, peppermint, a familiar and contex- tually inappropriate odor, was the conceptual equivalent of the odors used by Schab. However, had clean fresh pine been the only odor examined, CDM effects would not have been found. In previous work where odor context cue effects have failed, the ambient odors tested may not have been distinctive against the contextual background in which they appeared.

Support for the importance of contextual distinctiveness in relation to odor cue effectiveness was also revealed by subjects' commentary during debriefing. In both experiments, several subjects in the clean fresh pine conditions commented that they had dismissed the presence of the ambient odor because they assumed it simply indicated that the room had just been cleaned. By contrast, several subjects in the osmanthus and peppermint ambient odor conditions remarked that they thought the room odor was suspicious and may have had something to do with the experiment. A shortcoming of the present research was that subjects were not directly asked to rate the "distinctiveness" of the specific odors tested. Thus the influence of contextual distinctiveness per se remains deduced from performance in relation to the odor cue characteristics post hoc.

Sex differences were not found to contribute to the present findings. Although some research has reported a female advantage in olfactory processing (Doty et al., 1981; Kirk-Smith et al., 1983), this is usually when odor concentrations are at subthreshold levels (Whisman, Goetzinger, Cotton, \& Brinkman, 1978). The absence of sex differences is consistent with many studies in which superthreshold odor concentrations have been used (e.g., Herz \& Cupchik, 1995; Lyman \& McDaniel, 1990; Schab, 1990).

More research is currently needed to elucidate the factors that contribute to odor cue potency in CDM. In the present experiments, contextual distinctiveness was defined in terms of the thematic appropriateness of an odor to the laboratory environment. The relation of the hedonic characteristics of an odor (pleasant-unpleasant) and its interaction with contextual appropriateness should also be examined. In addition, studies in which several novel odors are examined together, and in which the same odors serve as contextually distinctive and nondistinctive cues respectively, now need to be conducted.

\section{REFERENCES}

Bjork, R. A., \& Richardson-KLavehn, A. (1989). On the puzzling relationship between environmental context and human memory. In C. Izawa (Ed.), Current issues in cognitive processes (pp. 313-344). Hillsdale, NJ: Erlbaum

Brown, W. P., \& URE, D. M. J. (1969). Five rated characteristics of 650 word association stimuli. British Journal of Psychology, $\mathbf{6 0}$, 233-249.

CANN, A., \& Ross, D. A. (1989). Olfactory stimuli as context cues in human memory. American Journal of Psychology, 102, 91-102.

Dalton, P. (1993). The role of stimulus familiarity in contextdependent recognition. Memon' \& Cognition, 21, 223-234.

Doty, R. L., SNyder, P., Huggins, G. , \& Lowry, L. D. (1981). Endocrine. cardiovascular and psychological correlates of olfactory sen- 
sitivity changes during the human menstrual cycle. Journal of Comparative \& Physiological Psychology, 95, 45-60.

EICH, J. E. (1980). The cue-dependent nature of state-dependent retrieval. Memory \& Cognition, 8, 157-173.

EICH, [J.] E., Macaulay, D., \& RYAN, L. (1994). Mood dependent memory for events of the personal past. Journal of Experimental Psychology: General, 123, 201-215.

Fernandez, A., \& GlenberG, A. M. (1985). Changing environmental context does not reliably affect memory. Memory \& Cognition, $13,333-345$

HERZ, R. S. (in press). Emotion experienced during encoding enhances odor retrieval cue effectiveness. American Journal of Psychology.

HeRz, R. S., \& CupchiK, G. C. (1992). An experimental characterization of odor-evoked memories in humans. Chemical Senses, 17, 519-528.

Herz, R. S., \& CuPChIK, G. C. (1995). The emotional distinctiveness of odor-evoked memory. Chemical Senses, 20, 517-528.

JACOBY, L. L., \& CRAIK, F. I. M. (1979). Effects of elaboration of processing at encoding and retrieval: Trace distinctiveness and recovery of initial context. In L. S. Cermak \& F. I. M. Craik (Eds.), Levels of processing in human memory (pp. 1-22). Hillsdale, $\mathrm{NJ}$ : Erlbaum.

Kirk-Smith, M. D., VAN Toller, C., \& Dodd, G. H. (1983). Unconscious odour conditioning in human subjects. Biological Psychiatry, 17, 221-231.

LAWLESS, H., \& ENGEN, T. (1977). Associations to odors: Interference, mnemonics, and verbal labelling. Journal of Experimental Psychology, 3, 52-59.

Lyman, B. J., \& MCDANiEL, M. A. (1990). Memory for odors and odor names: Modalities of elaboration and imagery. Journal of Experimental Psychology: Learning, Memory, \& Cognition, 16, 656-664.

$\mathrm{SCHAB}, \mathrm{F}$. R. (1990). Odors and the remembrance of things past. Journal of Experimental Psychology: Learning, Memory, \& Cognition, 16, 648-655.

ScHMIDT, S. R. (1991). Can we have a distinctive theory of memory? Memory \& Cognition, 19, 523-542.

Smith, D. G., Standing, L., \& DE MaN, A. (1992). Verbai memory elicited by ambient odor. Perceptual \& Motor Skills, 74, 339-343.

Smith, S. M. (1988). Environmental context-dependent memory. In G. M. Davies \& D. M. Thomson (Eds.), Memory in context: Context in memory. Toronto: Wiley.

Tulving, E. (1983). Elements of episodic memory. Oxford: Oxford University Press.

Warren, C., \& Warrenburg, S. (1993). Mood benefits of fragrance. Perfumer \& Flavorist, 18, 9-16.

Whisman, M. L., Goetzinger, J. W., Cotton, F. O., \& Brinkman, D. W. (1978). Odorant evaluation: A study of ethanethiol and tetrahydrothiophene as warning agents in propane. Environment, Science \& Technology, 12, 1285-1288.

(Manuscript received July 28, 1995 revision accepted for publication January 15, 1996. . 